Synthesis, part of a Special Feature on Urban Sprawl

\title{
Urban Landscapes and Sustainable Cities
}

\author{
Erik Andersson $^{1}$
}

\begin{abstract}
Ecological research targeting sustainable urban landscapes needs to include findings and methods from many lines of ecological research, such as the link between biodiversity and ecosystem function, the role of humans in ecosystems, landscape connectivity, and resilience. This paper reviews and highlights the importance of these issues for sustainable use of ecosystem services, which is argued to be one aspect of sustainable cities. The paper stresses the need to include social and economic factors when analyzing urban landscapes. Spatially explicit data can be used to assess the roles different green areas have in providing people with ecosystem services, and whether people actually have access to the services. Such data can also be used to assess connectivity and heterogeneity, both argued to be central for continuous, long-term provision of these services, and to determine the role urban form has for sustainability.
\end{abstract}

Key Words: ecosystem function; landscape scale; sustainable development; urban ecology

\section{INTRODUCTION}

The rapid and worldwide urbanization of the human population raises concerns about the sustainability of cities. Sustainable development is a broad term generally thought to include equity, and economic and environmental concerns. As the Brundtland report states, sustainable development “...seeks to meet the needs and aspirations of the present without compromising the ability to meet those of the future" (United Nations World Commission on Environment and Development 1987). The issue is obviously subjective as it debates the way things ought to be and how we ought to live. Yet even so, there are some elements that should be included in any sustainability discourse, and the focus of this article is on one of them: functioning ecosystems. The article reviews and discusses the importance of ecosystems within cities and how cities can be analyzed as landscapes.

The word urban has a number of meanings related to a variety of conditions, such as population density, land cover, or cultural practices, with most authors using their own definition, or none (reviewed in McIntyre et al. 2000). Still, urbanization is something tangible that influences the environment, e.g., through increased air temperature and changed water cycles, and by altering ecological processes. In terms of shape rather than processes, urbanization results in an environment that is compositionally more heterogeneous, geometrically more complex, and ecologically more fragmented (Zhang et al. 2004), and may represent the most complex mosaic of vegetative land cover and multiple land uses of any landscape (Foresman et al. 1997). The roles of spatial heterogeneity and spatial/temporal scale are increasingly understood as essential for an understanding of ecological processes (e.g., Wiens 1989, Levin 1992, Drayton and Primack 1996, Watson 2002). Cities are interesting as they are dominated by one species, humans, and social and cultural factors are strongly involved in the shaping of system identity (Grimm et al. 2000, Pickett et al. 2001, Elmqvist et al. 2004). Yet our knowledge and understanding of the effects of these traits on urban landscapes and their ecology is far from complete.

From a self-sufficiency point of view there is no such thing as a sustainable city. Cities have always been dependent on their hinterlands for food and other ecosystem goods and services (e.g., Folke et al. 1997, Rees 1997, 2003). The regional or even global impact cities thus have stresses the important pedagogical role of functioning ecosystems in cities, especially as urbanization is increasingly disconnecting people from the nature that supports 
them (Pyle 1978, 1993, Miller 2005). To gain the much needed, broad-based public support for ecosystem preservation as well as more sustainable consumer demands, the places where people live and work need to be designed so as to offer opportunities for meaningful interactions with the natural world (Miller 2005). Apart from the educational value, urban systems also provide their inhabitants with a number of ecosystem services, some recognized and others unacknowledged. These ecosystem services are products of ecosystem processes and functions (Daily 1997) and include supporting (e.g., increased biodiversity, habitat, soil formation, ecological memory, seed dispersal, pollination, and storage and cycling of nutrients), cultural (recreation, enhancement of property value, community cohesion, source of knowledge), provisioning (e.g., food, water, fuel), and regulating (noise reduction, modulation of temperature, removal of air pollution, protection of water quality, etc.) services (Flores et al. 1998, Bolund and Hunhammar 1999, Jansson and Nohrstedt 2001, Millennium Ecosystem Assessment 2005). Many of these services are essential for human well-being (Chiesura 2004, and references therein) and thus an important aspect of liveable cities. The capacity, however, of a city to provide these services depends on the configuration of its ecosystems, and cannot be taken for granted. Nor are the services evenly distributed in space, and urban landscapes must be planned to ensure the citizens' access to important services. Ecological research targeting sustainable management of urban environments should include findings and methods from many lines of ecological research, such as the link between biodiversity and ecosystem function, the role of humans in ecosystems, landscape ecology, and resilience.

Issues of management and sustainable use of urban landscapes require some kind of theoretical framework to set goals and evaluate results. Resilience theory is arguably one of the most suitable in urban environments because it allows integration of ecosystem function with social dynamics. The definition of ecological resilience used here is given by Folke et al. (2004): it is the capacity of a system to absorb disturbance and reorganize while undergoing change so as to retain essentially the same function, structure, identity, and feedbacks. Urban landscapes are best described as socioecological systems where natural and social processes together shape the ecosystems. Such systems are self-aware, and non-genetic information plays an important role in system dynamics, which adds to resilience the dimensions of learning, anticipation, and potential for active transformation (Berkes et al. 2003, Olsson et al. 2004). However, this paper will focus on the spatial aspects of resilience.

\section{ISSUES IN URBAN ECOLOGY}

\section{Biological Diversity and Ecosystem Functions}

Little has been written on the importance of the species present in the city for the provision of ecosystem services or resilience. Changing the species diversity, abundance, and community composition may have functional consequences because the number and kinds of species present determine the efficacy of many ecological functions (see, e.g., Holling 1973, Chapin et al. 1998, Rosenfeld 2002, Norberg 2004). High numbers of species with similar ecological roles increase the number of potential community organizations that can uphold similar ecosystem functions, which makes the system resilient. Which species are found in urban green areas has to do with both internal factors and landscape context (Flores et al. 1998). Several urban bird communities are rescued by their surroundings, evidenced by strong correlations between certain species and landscape forest cover and parks (Melles et al. 2003). The individual patch may also have an influence on its surroundings, e. g., by providing ecosystem services to areas that are much larger than the patch itself (Bodin et al. 2006). The urban landscape mosaic is quite complex, with residential, commercial, industrial, governmentinstitutional, cultural-educational land uses, patches of remnant vegetation, secondary green areas such as parks or cemeteries, and other land uses; all of them more or less suited as habitat for different species.

\section{Ecological Processes and Social Drivers}

Cities are subjected to a strong human influence, and management decisions have profound implications for ecosystem function. One of the central tenets in landscape ecology is that processes can be inferred from geographical patterns, but it may not be that straightforward in urban landscapes where human activities both transcend habitat boundaries and differ between patches of the same habitat. Instead, urban landscapes may be conceived of as composites of many different types of 
influence, all expressed on a single surface plane. Some natural processes are rarely allowed to run their courses, and then only to a limited extent in restricted areas or under limited time periods (Dow 2000). Others are, at least to some extent, replaced by anthropogenic processes; e.g., all socioecological systems are exposed to two different selective forces at the same time, i.e., natural and cultural selection, the latter guided by human ideas and preferences. These two may work in concert, but they may also work in opposite directions. When human land-use intensity reaches a certain point, the system moves from being controlled by biotic and abiotic factors toward being controlled by human preferences, and the limiting factor will then be the financial means to realize these preferences (Hope et al. 2003). It is important to identify the processes controlled or strongly influenced by human activities because these are likely to cause deviating system behavior, such as arrested successions or changed seasonality. For example, early successional stages are common, and the number of possible successional pathways is extremely high (Alberti et al. 2003). Although arrested successional stages have their own stability, it is dependent on the occurrence of the arresting factor. However, the farther from a "natural" state the system is kept, the more resource demanding and dependent on continuous management will it be.

Much of the heterogeneity present in cities is probably a result of a wide range of different management objectives and practices (Grimm and Redman 2004, Barthel et al. 2005). Land management decisions themselves occur at multiple spatial scales driven by the scale of influence of the decision maker (Conroy et al. 2003), whose decisions can be expected to influence very different processes and ecosystem functions. For example, the activities of the single homeowner will have a direct impact on individuals of smaller, less vagile species and local soil processes, whereas it is the collective actions of a whole neighborhood that will affect larger species or population dynamics (e.g., Lepczyk et al. 2004). Some of the management routines are adjusted on a daily basis while others are restricted in practice by legislation and regulation (Dow 2000). Legacies from historical land uses have been shown to be pervasive (e.g., Foster et al. 2003) and urban green areas, especially in old cities, may have a quite varied land-use history, which could potentially help explain the high biodiversity found in old parks.

\section{Connectivity and Spatial Resilience}

Connectivity is defined here as the degree to which habitat for a species is continuous or traversable across a spatial extent. No landscape is inherently fragmented or connected, and can only be assessed in the context of an organism's ability or willingness (Harris and Reed 2002) to move between patches and the scale at which the organism interacts with the landscape (e.g., D'Eon et al. 2002). There are two aspects of connectivity, the continuity of a certain habitat (structural connectivity) and the possibility for organisms to move within or between patches (functional connectivity). Landscapes are often described as consisting of patch and matrix habitat, the latter defined as the most extensive and connected habitat of a landscape (Forman 1995), and as such, the matrix can potentially have a great influence on the species dynamics in the landscape (Rodewald 2003). There is a growing appreciation among landscape modelers that the configuration of the matrix can be of great importance for landscape connectivity, species dispersal, and habitat use, and that the matrix is rarely homogeneous (e.g., Gustafson and Gardner 1996, Ricketts 2001, Verbeylen et al. 2003, Revilla et al. 2004). The permeability and overall landscape composition will be perceived differently by different organisms (e.g., MacArthur and Levins 1964, Johnson et al. 1992, Hostetler and Holling 2001), which is why it is problematic to apply a binary matrix model to real urban landscapes. The effective distance between patches is a result of landscape permeability (i.e., how suitable a habitat is or how permeable it is to movement) as well as geographical distance, and dispersal across continuous landscapes is more frequent and faster than across binary landscapes (Malanson 2003). Effective distance has been shown to offer a better explanation for population dynamics than geographical distance alone (Verbeylen et al. 2003).

Spatial resilience deals with the ability of interconnected ecosystems to persist on a regional level (Nyström and Folke 2001). The capacity to reorganize after a disturbance event is related to a patch's connections with its surroundings as well as internal factors and has been called ecological memory (Nyström and Folke 2001, Bengtsson et al. 2003). The ecological memory is the network of species, their interactions in space and time, and includes the life-history experience with environmental fluctuations. Long-range dispersal has a positive effect on persistence in dynamic landscapes as it 
increases the number of couplings between patches. The trajectory of a disturbed patch undergoing reorganization is influenced by the access to different source areas and the dispersal ability of different organisms. However, no degree of connectivity between green areas will suffice to overcome critical deficiencies in their combined ecological content. Landscape heterogeneity, created by, e.g., multiple, contemporaneous successional stages, is a prerequisite for ecological memory (Berkes and Folke 2002) and provides insurance against uncertainty (Folke et al. 1996). There is a seeming paradox one has to deal with when discussing connectivity: on the one hand, connectivity facilitates movement between systems and is a prerequisite for spatial resilience and ecological memory; on the other, isolation or modularity prevents synchronicity over large scales and buffers against cascades of disaster and disease epidemics (Levin 1998).

\section{DISCUSSION}

\section{The Cityscape, Urban Ecology from a Landscape Perspective}

To comprehend and manage cityscapes, processes and functions must be understood and linked to their spatial, ecological, and social origin (Grimm and Redman 2004). The relation between ecological characteristics (e.g., the presence of different functional groups) and the ecosystems services people enjoy in cities is incompletely understood, and, because urban development is guided by human values, there is a need to inform people about the ecological requirements for the ecosystem services that increase human well-being. Many of these services depend on the species present in different green areas, and the presence of these species is, in turn, a result of a number of factors, socioeconomical as well as ecological. Consequently, different green areas will have different ecological functions and thus offer different ecosystem services. To ensure that the flow and access to ecosystem services is not interrupted, at least at the citywide scale, representative successional stages and different kinds of green areas in different urban contexts should be planned and managed for (Flores et al. 1998, see also Nyström and Folke 2001, Bengtsson et al. 2003). Many of the ecosystem services that have been described as important are by their nature highly subjective and likely to change. This, I argue, is just another strong reason to maintain resilient cityscapes with the ability to adapt to future needs. Heterogeneity has been argued to increase resilience in ecosystems, and it might be that this tenet holds true also for other aspects of socioecological systems. For example, an area with a diverse set of management practices based on different values might be better prepared to cope with changes in the environment or in the perception of desired ecosystem services among the human users.

It has been claimed that the ecological character of cityscapes can be described by adding layers of social and economical information to land cover maps (e.g., Redman et al. 2004). The resultant multilayered information on the ecology of every patch in the city can then be used to assess their different roles in providing people with ecosystem services. The proximity to other similar areas is crucial for the maintenance of ecological properties within a patch, especially for smaller patches that are more likely to lose species over time (Drayton and Primack 1996). Analogously to reorganization after disturbance, the success of restoration projects is strongly influenced by the connections to existing green areas (Robinson and Handel 1993, 2000). Analyses of more comprehensive data sets may also help us understand the role of urban form; there has, for example, been a long-standing debate on whether compact cities or urban sprawl are most sustainable (see, e.g., Wiersinga 1997). However, as shown in a review by Neuman (2005), it is not the form itself that is sustainable or not, but the processes that create and are in turn shaped by the form. The combination of ecological and social information should be able to capture important processes in the landscape and determine their origin and implications for sustainability, e.g., how citizens' access to different ecosystem services affects their choices and actions.

Responses to this article can be read online at:

http://www.ecologyandsociety.org/voll1/iss1/art34/responses/

\section{Acknowledgments:}

I would like to thank to Maria Tengö and Thomas Elmqvist, whose comments and ideas helped to improve this paper. 


\section{LITERATURE CITED}

\begin{abstract}
Alberti, M., J. M. Marzluff, E. Shulenberger, G. Bradley, C. Ryan, and C. Zumbrunnen. 2003. Integrating humans into ecology: opportunities and challenges for studying urban ecosystems. Bioscience 53:1169-1179.
\end{abstract}

Barthel, S., J. Colding, T. Elmqvist, and C. Folke. 2005. History and local management of a biodiversity-rich, urban, cultural landscape. Ecology and Society 10(2):10. [online] URL: http:/ /www.ecologyandsociety.org/vol10/iss2/art10/.

Bengtsson, J., P. Angelstam, T. Elmqvist, U. Emanuelsson, C. Folke, M. Ihse, F. Moberg, and M. Nyström. 2003. Reserves, resilience and dynamic landscapes. Ambio 32:389-396.

Berkes, F., and C. Folke. 2002. Back to the future: ecosystem dynamics and local knowledge. Pages 121-146 in L. Gunderson and C. S. Holling, editors. Panarchy. Understanding transformations in human and natural systems. Island Press, Washington D.C., USA.

Berkes, F., J. Colding, and C. Folke, editors. 2003. Navigating social-ecological systems. Building resilience for complexity and change. Cambridge University Press, Cambridge, UK.

Bodin, Ö., M. Tengö, A. Norman, J. Lundberg, and T. Elmqvist. 2006. The value of small size: loss of forest patches and threshold effects on ecosystem services in southern Madagascar. Ecological Applications, in press.

Bolund, P., and S. Hunhammar. 1999. Ecosystem services in urban areas. Ecological Economics 29:293-301.

Chapin, F. S., O. E. Sala, I. C. Burke, J. P. Grime, D. U. Hooper, W. K. Lauenroth, A. Lombard, H. A. Mooney, A. R. Mosier, S. Naeem, S. W. Pacala, J. Roy, W. L. Steffen, and D. Tilman. 1998. Ecosystem consequences of changing biodiversity - experimental evidence and a research agenda for the future. Bioscience 48:45-52.

Chiesura, A. 2004. The role of urban parks for the sustainable city. Landscape and Urban Planning 68:129-138.

Conroy, M. J., C. R. Allen, J. T. Peterson, L. J.
Pritchard, and C. T. Moore. 2003. Landscape change in the Southern Piedmont: challenges, solutions, and uncertainty across scales. Conservation Ecology 8(2):3. [online] URL: http://www.consecol. org/vol8/iss2/art3/.

Daily, G. 1997. Nature's services. Island Press, Washington, D.C., USA.

D'Eon, R. G., S. M. Glenn, I. Parfitt, and M.-J. Fortin. 2002. Landscape connectivity as a function of scale and organism vagility in a real forested landscape. Conservation Ecology 6(2):10. [online] URL: http://www.ecologyandsociety.org/vol6/iss2/ $\underline{\operatorname{art10/}}$.

Dow, K. 2000. Social dimensions of gradients in urban ecosystems. Urban Ecosystems 4:255-275.

Drayton, B., and R. B. Primack. 1996. Plant species lost in an isolated conservation area in metropolitan Boston from 1894 to 1993. Conservation Biology 10:30-39.

Elmqvist, T., J. Colding, S. Barthel, S. Borgstrom, A. Duit, J. Lundberg, E. Andersson, K. Ahrne, H. Ernstson, C. Folke, and J. Bengtsson. 2004. The dynamics of socialecological systems in urban landscapesStockholm and the National Urban Park, Sweden. Pages 308-322 in C. Alfsen-Norodom, B. D. Lane, and M. Corry, editors. Urban biosphere and society: partnership of cities. Annals of the New York Academy of Sciences, New York, New York, USA.

Flores, A., S. T. A. Pickett, W. C. Zipperer, R. V. Pouyat, and R. Pirani. 1998. Adopting a modern ecological view of the metropolitan landscape: the case of a greenspace system for the New York City region. Landscape and Urban Planning 39:295308.

Folke, C., C. S. Holling, and C. Perrings. 1996. Biological diversity, ecosystems, and the human scale. Ecological Applications 6:1018-1024.

Folke, C., A. Jansson, J. Larsson, and R. Costanza. 1997. Ecosystem appropriation by cities. Ambio 26:167-172.

Folke, C., S. Carpenter, B. Walker, M. Scheffer, T. Elmqvist, L. Gunderson, and C. S. Holling. 2004. Regime shifts, resilience, and biodiversity in ecosystem management. Annual Review of Ecology, 
Evolution, and Systematics 35:557-581.

Foresman , T. W., S. T. A. Pickett, and W. C. Zipperer 1997. Methods for spatial and temporal land use and land cover assessment for urban ecosystems and application in the greater Baltimore-Chesapeake region. Urban Ecosystems 1:201-216.

Forman, R. T. T. 1995. Land mosaics. Cambridge University Press, Cambridge, UK.

Foster, D., F. Swanson, J. Aber, I. Burke, B. Nicholas, D. Tilman, and A. Knapp. 2003. The importance of land-use legacies to ecology and conservation. Bioscience 53:77-88.

Grimm, N. B., J. M. Grove, S. T. A. Pickett, and C. L. Redman. 2000. Integrated approaches to long-term studies of urban ecological systems. Bioscience 50:571-584.

Grimm, N. B., and C. L. Redman. 2004. Approaches to the study of urban ecosystems: the case of Central Arizona-Phoenix. Urban Ecosystems 7:199-213.

Gustafson, E. J., and R. H. Gardner. 1996. The effect of landscape heterogeneity on the probability of patch colonization. Ecology 77:94-107.

Harris, R. J., and J. M. Reed. 2002. Behavioral barriers to non-migratory movements of birds. Annales Zoologici Fennici 39:275-290.

Holling, C. S. 1973. Resilence and stability of ecological systems. Annual Review of Ecology and Systematics 4:1-23.

Hope, D., C. Gries, W. X. Zhu, W. F. Fagan, C. L. Redman, N. B. Grimm, A. L. Nelson, C. Martin, and A. Kinzig. 2003. Socioeconomics drive urban plant diversity. Proceedings of the National Academy of Sciences of the United States of America 100:8788-8792.

Hostetler, M., and C. S. Holling. 2001. Detecting the scales at which birds respond to structures in urban landscapes. Urban Ecosystems 4:25-54.

Jansson, ^., and P. Nohrstedt. 2001. Carbon sinks and human freshwater dependence in Stockholm County. Ecological Economics 39:361-370.
Johnson, A. R., J. A. Wiens, B. T. Milne, and T. O. Crist. 1992. Animal movements and population dynamics in heterogeneous landscapes. Landscape Ecology 7:63-75.

Lepczyk, C. A., A. G. Mertig, and J. G. Liu. 2004. Assessing landowner activities related to birds across rural-to-urban landscapes. Environmental Management 33:110-125.

Levin, S. A. 1992. The problem of pattern and scale in ecology. Ecology 73:1943-1967.

Levin, S. A. 1998. Ecosystems and the biosphere as complex adaptive systems. Ecosystems 1:431-436.

MacArthur, R., and R. Levins. 1964. Competition, habitat selection, and character displacement in a patchy environment. Proceedings of the National Academy of Science 51:1207-1210.

Malanson, G. P. 2003. Dispersal across continuous and binary representations of landscapes. Ecological Modelling 169:17-24.

McIntyre, N. E., K. Knowles-Yanez, and D. Hope. 2000. Urban ecology as an interdisciplinary field: differences in the use of "urban" between the social and natural sciences. Urban Ecosystems 4:5-24.

Melles, S., S. Glenn, and C. Martin. 2003. Urban bird diversity and landscape complexity: speciesenvironment associations along a multiscale habitat gradient. Conservation Ecology 7(1):5. [online] URL: http://www.consecol.org/vol7/iss1/art5/.

Millennium Ecosystem Assessment. 2005. Ecosystems and human well-being. Island Press, Washington, D.C., USA.

Miller, J. R. 2005. Biodiversity conservation and the extinction of experience. Trends in Ecology \& Evolution 20:430-434.

Neuman, M. 2005. The compact city fallacy. Journal of Planning Education and Research 25:11-26.

Norberg, J. 2004. Biodiversity and ecosystem functioning: a complex adaptive systems approach. Limnology and Oceanography 49:1269-1277.

Nyström, M., and C. Folke. 2001. Spatial resilience of coral reefs. Ecosystems 4:406-417. 
Olsson, P., C. Folke, and T. Hahn. 2004. Socialecological transformation for ecosystem management: the development of adaptive co-management of a wetland landscape in southern Sweden. Ecology and Society 9(4):2. [online] URL: http://www.ecolo gyandsociety.org/vol9/iss4/art2/.

Pickett, S. T. A., M. L. Cadenasso, J. M. Grove, C. H. Nilon, R. V. Pouyat, W. C. Zipperer, and R. Costanza. 2001. Urban ecological systems: linking terrestrial ecological, physical, and socioeconomic components of metropolitan areas. Annual Review of Ecology and Systematics 32:127-157.

Pyle, R. M. 1978. The extinction of experience. Horticulture 56:64-67.

Pyle, R. M. 1993. The thunder tree: lessons from an urban wildland. Beacon Press, Boston, Massachussetts, USA.

Redman, C. L., J. M. Grove, and L. H. Kuby. 2004. Integrating social science into the long-term ecological research (LTER) network: social dimensions of ecological change and ecological dimensions of social change. Ecosystems 7:161171.

Rees, W. E. 1997. Urban ecosystems: the human dimension. Urban Ecosystems 1:63-75.

Rees, W. E. 2003. Understanding urban ecosystems: an ecological economics perspective. Pages 115-136 in A. R. Berkowitz, C. H. Nilon, and K. S. Hollweg, editors. Understanding urban ecosystems. A new frontier for science and education. Springer-Verlag, New York, New York, USA.

Revilla, E., T. Wiegand, F. Palomares, P. Ferreras, and M. Delibes. 2004. Effects of matrix heterogeneity on animal dispersal: from individual behavior to metapopulation-level parameters. American Naturalist 164:E130-E153.

Ricketts, T. H. 2001. The matrix matters: effective isolation in fragmented landscapes. American Naturalist 158:87-99.

Robinson, G. R., and S. N. Handel. 1993. Forest restoration on a closed landfill: rapid addition of new species by bird dispersal. Conservation Biology 7:271-278.
Robinson, G. R., and S. N. Handel. 2000. Directing spatial patterns of recruitment during an experimental urban woodland reclamation. Ecological Applications 10:174-188.

Rodewald,A.D. 2003. The importance of land uses within the landscape matrix. Wildlife Society Bulletin 31:586-592.

Rosenfeld, J. S. 2002. Functional redundancy in ecology and conservation. Oikos 98:156-162.

United Nations World Commission on Environment and Development. 1987. Our common future. Oxford University Press, New York, New York, USA.

Verbeylen, G., L. De Bruyn, F. Adriaensen, and E. Matthysen. 2003. Does matrix resistance influence red squirrel (Sciurus vulgaris L. 1758) distribution in an urban landscape? Landscape Ecology 18:791-805.

Watson, D. M. 2002. A conceptual framework for studying species composition in fragments, islands and other patchy ecosystems. Journal of Biogeography 29:823-834.

Wiens, J. A. 1989. Spatial scaling in ecology. Functional Ecology 3:385-397.

Wiersinga, W. 1997. Compensation as a strategy for improving environmental quality in compact cities. Bureau SME, Amsterdam, Netherlands.

Zhang, L., W. Jianping, Z. Yu, and S. Jiong. 2004. A GIS-based gradient analysis of urban landscape pattern of Shanghai metropolitan area, China. Landscape and Urban Planning 69:1-16. 